Bangladesh J. Pl. Breed. Genet., 26(2): 09-14, 2013

\title{
GENETIC DIVERGENCE ON QUANTITATIVE CHARACTERS OF EXOTIC MAIZE INBREDS (Zea mays L.)
}

\author{
M. G. Azam, U. K. Sarker ${ }^{1}$, M. A. K. Mian', B. R. Banik and M. Z. A. Talukder \\ Bangladesh Agricultural Research Institute \\ Gazipur 1701, Bangladesh
}

\begin{abstract}
Forty nine CIMMYT, India Maize inbred lines were characterized based on some morphological traits and grain yield. Genetic divergences of inbred lines of maize were estimated using $\mathrm{D}^{2}$ and principal component analysis. The genotypes under study fell into five clusters. The inter cluster distance were higher than intra cluster distance suggesting wider genetic diversity among the genotypes of different groups. The maximum intra cluster value was observed in cluster IV and minimum in cluster $\mathrm{V}$. The inter cluster $\mathrm{D}^{2}$ values revealed that the maximum distance among the cluster. The highest inter cluster distance was observed between cluster II \& I and the lowest inter cluster distance was illustrated in cluster III \& I. The cluster means were higher for days to $50 \%$ tasseling, days to $50 \%$ sillking, plant height, ear height, cob length, number of rows per cob, number of grains per row in cluster IV; cob diameter and grain yield per plant was found higher in cluster II. It is expected that crossing of inbred lines belonging high to medium $\mathrm{D}^{2}$ values tend to produce high heterosis for yield.
\end{abstract}

Keywords: Maize; divergence; cluster analysis; yield; Bangladesh

\section{INTRODUCTION}

Maize (Zea mays L.) plays a significant role in human and livestock nutrition (food, feed, fodder, fuel and like medical and ornamental plant) in worldwide (Alahdadi et al. 2011; Khodarahmpour, 2011). It is the world most widely grown cereal and is the primary staple food in many developing countries (Morris et al. 1999). It is a golden crop living the highest capacity to convert the solar energy to grain. Maize in Bangladesh is becoming an important crop in the rice based cropping system. It is the $3^{\text {rd }}$ leading important cereal crop after rice and wheat. Only maize can yield more than rice and wheat (Elias, 1995). Introduction of hybrid varieties and appropriate management practices increased area, production and yield increased by $19.83 \%, 34.40 \%$ and $14.56 \%$ respectively for the year 1987 to 2004 (Moniruzzaman et al. 2007). According to DAE maize area is 3.12 lac ha in 2012-2013 and total production is 21.78 lac tons and average yield in $6.98 \mathrm{ton} / \mathrm{ha}$ (Annous, 2014). The area and production of maize is increasing day by day in Bangladesh and it continues to expand rapidly at an average rate of $20 \%$ per year (Annous, 2008).

Hybridization prospective parent (inbred lines) selection is a pre-requisite work for hybrids development. Several studies on maize have shown that an inbred line from diverse stocks tends to be more productive than crosses of inbred lines from the some

\footnotetext{
${ }^{1}$ Department of Genetics and Plant Breeding, Bangabandhu Sheikh Mujibur Rahman Agricultural University, Gazipur 1706, Bangladesh.
} 
variety (Vasal, 1998). Saxena et al. (1998) also reported that manifestation of heterosis usually depends on the genetic divergence of the two parental lines. The qualification of genetic diversity through biometrical procedure made it possible to choose genetically diverse parents. Multivariate analysis is a useful tool in quantifying the degree of divergence between biological population at genotypic level and to assess relative contribution of different components to the total divergence both at the intra-cluster and inter-cluster levels (Murty and Arunachalam, 1966; Ram and Panwar, 1970; Sachan and Sharma, 1971). Genetic diversity is one of the useful tools to select appropriate genotypes for hybridization. Evaluation of genetic diversity is an important to know the sources of genes for particular trait within the available germplasm (Tomooka, 1991). At present, there is no method for increasing atmospheric precipitation during drought periods. Therefore, the experiment was undertaken to find out suitable genotypes that could directly be used as open pollinated variety or parents for hybrid or synthetic variety.

\section{MATERIALS AND METHODS}

Forty nine genotypes of maize collected from CIMMYT, India were grown in a completely randomized block design with three replications at Bangladesh Agricultural Research Institute, Gazipur 1701 (AEZ 28 and 24.00"N latitude and $90^{\circ} .25^{\prime \prime E}$ longitude) in the season of 2010-11. The seeds were sown on November 29, 2010 the unit plot size was $25 \mathrm{~m}$ long and intra row spacing was $75 \mathrm{~cm}$ and $25 \mathrm{~cm}$ with one plant in each hill. Fertilizers were applied @ 120,80,80,20, 5 and $1 \mathrm{~kg} / \mathrm{ha}$ of $\mathrm{N}, \mathrm{P}_{2} \mathrm{Os}, \mathrm{K}_{2} \mathrm{O}, \mathrm{S}, \mathrm{Zn}$ and B respectively. Standard agronomic practices were done and plant protection measures were taken when required. Data on days to $50 \%$ tasseling (DT) and silking (DS) were recorded on whole plot basis. Ten randomly selected plants were used for recording observations on grain yield/plant $(\mathrm{g})$, plant height $(\mathrm{PLHT})(\mathrm{cm})$, ear height $($ ERHT) $(\mathrm{cm})$, Number of rows per cob, (R/COB) Number of grains per row (SEED/ROW), cob length (ERLT) $(\mathrm{cm})$, cob diameter (ERDIA) $(\mathrm{cm}), 1000$ grain weight (TGW) $(\mathrm{g})$. Genetic diversity was estimated using Mahalanabis generalized distance $\left(\mathrm{D}^{2}\right)$ extended by Rao (1952). Tocher's method was followed to determine the group constellation. Canonical variate analysis was also performed as per Rao (1964) to confirm the results of cluster $\mathrm{D}^{2}$ analysis. The data were analyzed using GENSTAT 5.0 and SPSS 11.6 software program.

\section{RESULTS AND DISCUSSION}

Principal component analysis revealed that the first axes accounted $36.586 \%$ of the total variation among the genotypes, while 10 of these with eigen values accounted for $99.15 \%$. The first three axes of 10 eigen values above the unity accounted $71.962 \%$ of the total variation among the ten characters describing 49 maize inbred lines. Range, mean, standard deviation of different characters of the studied inbred lines is presented in Table 1. From, this table we can see that high to medium variation was found in days to $50 \%$ silking, grain yield per plant $(\mathrm{g}), 1000$-seed weight, plant height $(\mathrm{cm})$ and ear height $(\mathrm{cm})$. The Lowest variation was observed from Cob diameter $(\mathrm{cm})$, Number of rows per cob and Cob length $(\mathrm{cm})$. Hence, there is enough scope for selection of potential inbred lines for hybridization program.

Forty nine inbred lines were grouped into five different clusters by using clustering techniques. The distribution of the genotypes in different clusters is presented in Table 2. The maximum number of genotypes (17) were grouped into cluster $\mathrm{V}$ followed by cluster III (15), whereas minimum number (2) in to cluster IV followed by 
cluster II (5). The cluster I consists of ten genotypes. Smith (1990) reported three groups in a divergence study of 48 maize cultivars.

Table 1. Briefly statistics of the quantity characters of exotic maize accessions

\begin{tabular}{l|c|cc|c}
\hline Characteristics & Mean & \multicolumn{2}{|c|}{ Range } & Standard \\
\cline { 3 - 4 } & & Min & Max & Deviation \\
\hline Days to 50\% tasseling & 95.714 & 84 & 114 & 6.06 \\
Days to 50\% silking & 98.878 & 87 & 198 & 78.49 \\
Plant height (cm) & 95.282 & 62.2 & 150.4 & 17.96 \\
Ear height (cm) & 32.755 & 14.1 & 68.6 & 11.85 \\
Cob length (cm) & 10.335 & 6.1 & 6.1 & 2.38 \\
Cob diameter (cm) & 11.241 & 16.8 & 14.1 & 1.46 \\
Number of rows per cob & 11.676 & 8 & 15 & 1.66 \\
Number of grains per row & 15.931 & 9.3 & 25.3 & 4.03 \\
1000-seed weight & 256.408 & 138 & 382 & 48.73 \\
Grain yield /plant (g) & 180.367 & 49 & 372 & 67.45 \\
\hline
\end{tabular}

Table 2. Pedigree number and different clusters of 49 maize inbred lines

\begin{tabular}{|c|c|c|}
\hline Cluster & No. of cluster & Pedigree number \\
\hline I & 10 & $\begin{array}{l}\text { P31C4S5B-39-\#-\#-B-B-B-B-B-7-B-3-B, CML424-1-B, CML435-2-B, } \\
\text { P31C4S5B-23-\#-\#-6-BBBB-B-B-B-3-B-2-B, CML-474-B-B-B-2-B, } \\
\text { P31C4S5B-41-\#-\#-B-B-B-B-B-B-2-B-2-B, P31C4S5B-33-\#-\#-8-B-B-B- } \\
\text { B-B-B-B-3-B, CML481-1-B, CA14514-1-B-1-B, }\end{array}$ \\
\hline II & 5 & $\begin{array}{l}\text { P31C4S5B-23-\#-\#-4-BBB-B-B-B-B-4-B, CML337-1-B, CML121-1-B, } \\
\text { CA03130-1-2-B-3-B, CML291-1-B }\end{array}$ \\
\hline III & 15 & $\begin{array}{l}\text { CML161-2-B, CML287-1-B, CA03139-6-4-2-B, P31C4S5B-41-\#-\#-B- } \\
\text { B-B-B-B-B-1-B-1-B, P31C4S5B-39-\#-\#-B-B-B-B-B-8-8-2-B, CA03130- } \\
\text { B-B-2-B-1-B, CA14514-B-2-B-2-B, CML290-2-B, P31C4S5B-39-\#-\#-B- } \\
\text { B-B-B-B-8-7-2-B, BH-21, CML172-2-B, CML112-1-B, CA14514-3-B-1- } \\
\text { B, CML41-2-B, CA03130-1-5-B-1-B }\end{array}$ \\
\hline IV & 2 & CML434-2-B, CML 425-B-B-B-4-B \\
\hline $\mathrm{V}$ & 17 & 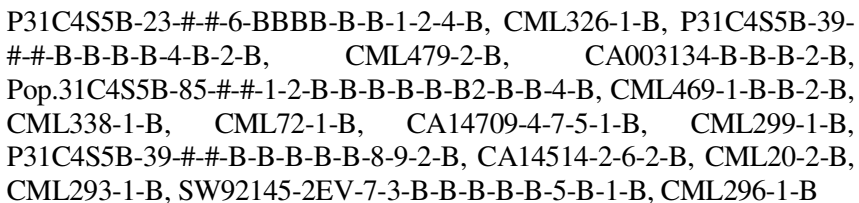 \\
\hline
\end{tabular}

The pattern of clustering revealed that the genotypes originated from same country did not form a single cluster. This indicates that geographic diversity is not always related to genetic diversity. Similar results have been reported by Das and Gupta (1984) in black gram and Mian et al. (1991) in Pea. Likewise the genotypes of similar origin were grouped in different clusters.

The intra-and inter-cluster values within and among the clusters are presented in Table 3. Intra-group distances appeared much smaller than the inter-groups, suggesting a lower genetic diversity among the lines of the same group than those from different groups. This is collaborated with the results of Ivy et al. (2007) and Hoque et al. (2008). Intra-cluster distances varied from 0.634 to 1.611 comparatively, higher intra-cluster 
distances were observed in cluster IV and I. Clustering revealed instability due to low divergence and widely diverged clusters remain stable in different environment reported by Raut $e$ al. (1985). Inter-cluster distances ranged from 3.328 to 8.731 . The maximum inter-cluster distance was observed between clusters II and I (8.731). Medium or intermediate distances were observed between cluster IV and I (6.743), V and IV (5.910) and V and II (4.485). The lowest distance was shown between cluster III and I (3.328). It indicated that the genotypes grouped in these clusters were highly divergent from each other. Selection of parents from the highly divergent clusters is expected to manifest high heterosis in crossing and also wide variability in genetic architecture. Murty and Arunachalam (1966) claimed that there is a positive relationship between the specific combining ability and the degree of genetic diversity.

Table 3. Inter and intra-cluster (bold) distance $\left(\mathrm{D}^{2}\right)$ for 49 maize inbred lines obtained by canonical variate analysis

\begin{tabular}{c|c|c|c|c|c}
\hline Cluster & I & II & III & IV & V \\
\hline I & $\mathbf{0 . 9 5 7 7}$ & & & & \\
II & 8.731 & $\mathbf{0 . 6 5 6 4}$ & & & \\
III & 3.328 & 7.211 & $\mathbf{0 . 7 3 8 3}$ & & \\
IV & 6.743 & 8.292 & 8.565 & $\mathbf{1 . 6 0 8 1}$ & \\
V & 4.545 & 4.485 & 3.983 & 5.910 & $\mathbf{0 . 6 3 3 9}$ \\
\hline
\end{tabular}

The genetic differences between clusters were reflected in their cluster means. Mean values for different clusters are presented in Table 4 . The highest mean values for days to $50 \%$ tasseling, days to $50 \%$ sillking, plant height, ear height, cob length, number of rows per cob, number of grains per row were observed in the same cluster IV. This means lines included in this group are better for these parameters. Cluster V had the lowest value for plant height and ear height. The lowest mean values for days to tasseling and days to silking were found in cluster III.

Table 4. Cluster means for 10 different characters of 49 maize inbred lines

\begin{tabular}{|c|c|c|c|c|c|}
\hline \multirow[t]{2}{*}{ Characters } & \multicolumn{5}{|c|}{ Clusters } \\
\hline & $\mathrm{I}$ & II & III & IV & $\mathrm{V}$ \\
\hline Days to $50 \%$ tasseling & 96.90 & 93.20 & 92.13 & 100.50 & 98.35 \\
\hline Days to $50 \%$ silking & 100.30 & 95.80 & 95.00 & 104.00 & 101.76 \\
\hline Ear height (cm) & 34.17 & 32.38 & 31.89 & 45.85 & 31.25 \\
\hline Plant height $(\mathrm{cm})$ & 98.70 & 91.18 & 97.09 & 110.65 & 91.07 \\
\hline Cob length $(\mathrm{cm})$ & 9.88 & 9.88 & 9.67 & 12.60 & 11.05 \\
\hline Cob diameter $(\mathrm{cm})$ & 10.40 & 12.26 & 11.25 & 11.30 & 11.42 \\
\hline Number of rows per cob & 11.37 & 12.24 & 11.03 & 12.60 & 12.15 \\
\hline Number of grains per row & 15.15 & 18.38 & 13.31 & 19.10 & 17.61 \\
\hline 1000-seed weight (g) & 238.00 & 260.00 & 315.67 & 84.50 & 234.12 \\
\hline Grain yield /plant (g) & 102.00 & 320.00 & 151.87 & 190.00 & 209.41 \\
\hline
\end{tabular}

Contribution of the characters towards divergence is presented in Table 5. The canonical analysis revealed that, days to $50 \%$ tasseling, 1000 seed weight (g), cob diameter and ear height $(\mathrm{cm})$ showed positives values in respect to both the vectors (Vector I and II). Such results indicate that these characters contributed maximum towards divergence of the genotypes. Jagadev and Samal (1991) and Patel et al., (1989) reported that plant height and seed yield were higher contributors towards diversity in niger and safflower, respectively. Thiagarjan et al., (1988) observed that plant height as 
higher contributor in cowpea. Maximum contribution of days to tasseling, kernel weight and kernel yield/plant $(\mathrm{g})$ towards diversity of maize was also reported by Ahloowallia (1963).

Table 5. Latent vectors for 10 principal component characters of 49 in maize inbred lines

\begin{tabular}{lcc}
\hline Characters & Vector I & Vector II \\
\hline Days to 50\% tasseling & 0.0707 & 0.1322 \\
Days to 50\% silking & -0.0653 & -0.0911 \\
Ear height $(\mathrm{cm})$ & 0.0342 & 0.0027 \\
Plant height $(\mathrm{cm})$ & 0.0240 & -0.0236 \\
Cob length $(\mathrm{cm})$ & 0.0120 & -0.0578 \\
Cob diameter $(\mathrm{cm})$ & 0.2248 & 0.4422 \\
Number of rows per cob & 0.1371 & -0.3892 \\
Number of grains per row & -0.1099 & 0.0913 \\
1000 seed weight & 0.0095 & 0.0333 \\
Grain yield /plant $(\mathrm{g})$ & -0.0351 & 0.0054 \\
\hline
\end{tabular}

Considering plant architecture and other traits the inbreds are clustered into 5 diverged groups. It is expected that inbred lines belonging high to medium $\mathrm{D}^{2}$ values tend to produce high heterosis for yield. On the basis of the findings of the present study, it can be recommended that the genotypes from cluster III, IV and V were selected to be the better parents for future hybridization program to obtain desirable segregates in respect of different yield and yield contributing characters. Hence major emphasis should be given on them for selecting parents for hybridization in maize.

\section{REFERENCES}

Ahloowallia, B. S. and N. L. Dhawn. 1963. Effect of genetic diversity on combining ability of inbred lines of maize (Zea mays L.), Indian J. Genet, 22: 260-262.

Alahdadi, I., H. Oraki and F. Parhizkarkhajani. 2011. Effect of water stress on yield and yield components of sunflower hybrids. Afr J Biotechnol. 10(34): 6504-6509.

Anonymous 2008. Achievements of the Bangladesh-CIMMYT partnership for agricultural research and development. CIMMYT-Bangladesh, Banani, Dhaka. pp. 1-9.

Anonymous 2014. Department of Agricultural Extension. Ministry of Agriculture, Bangladesh.

Araus, J. I., G. . Slafer. M. P. Reynolds and C. Toyo. 2002. Plant breeding and drought in C3 cereals. Ann. Bot. 89: 925-940.

Das, P. K. and T. D. Gupta. 1984. Multivariate analysis in blackgram. Indian J. Genet. 44(2): 243-247.

Elias, M. 1995. Promoting maize into production, consumption and utilization system: Challenge and Opportunity in the Proceeding of the National Maize Promoting Workshop, 26-27 June 1995. BARC, Farmgate, Dhaka. Pp. 1-2.

Hoque, M., M. Asaduzzaman, M. M. Rahman, S. Zaman and S. A. Begum. 2008. Genetic divergence in maize (Zea mays L.). Bangladesh J. Agric., 9:145-148.

Ivy, N. A., M. S. Uddin, R. Sultana and M. M. Masud. 2007. Genetic divergence in maize (Zea mays L.). Bangladesh J. Pl. Breed. Genet., 20: 53-56.

Jagadev, P. N., K. M. Samal and L. Lenka. 1991. Genetic divergence in rape mustard. Indian J. Genet. 51:465-466. 
Johnson, H. W., H. F. Robinson and R. E. Comstock.1955. Estimates of genetic and environmental variability in soybean. Agron. J. 47(7): 314-318.

Khodarahmpour, Z. 2011. Effect of drought stress induced by polyethylene glycol (PEG) on germination indices in corn (Zea mays L.) hybrids. Afr. J. Biotechnol. 10 (79): 18222-18227.

Mian, M. A. K., T. Hossain, K. Safuddiaand and M. W. Mia. 1991. Genetic divergence in some germplasm of pea (Pisium sativum L.). Ann. Bangladesh Agric. 1(2): 101-103.

Moniruzzaman, M. R., Karim, Q. M. Alam and M. S. Rahman. 2007. Technical efficiency of maize growers in some selected areas of Bangladesh. Project Report 2006-07. Economics Division, BARI, Gazipur. pp. 1-3.

Morris, M. L., J. Risopoulos and D. Beck. 1999. Genetic change in farmer-recycled maize seed; a review of the evidence. CIMMYT Economic Working Paper No. 99-07. Mexico, D.F., CIMMYT, 1 p.

Murty, B. R. and V. Arunachalam, 1966. Genetic divergence in wheat under different environmental condition. Cereal Res. Comm. 6: 307-317.

Patel, M. A. M. V. Reddi., B. S. Ranaand and B. J. Reddy. 1989. Genetic divergence in safflower (Carthamus tinctorius L.). Indian J. Genet. 49: 113-118.

Ram, J. and D. V. S. Panwar. 1970. Interspecific divergence in rice (Oryza sativa L.) Indian J. Genet., 30: 1-2.

Rao, C. R. 1952. Advanced statistics methods in Biometric Research, Ed. John Wiley and Sons Inc. New York. p390.

Rao, C. R. 1964. Statistical genetic consideration for maintaining germplasm collection. Theor Appl. Genet. 86: 673-678.

Raut, R. G. and B. R. Murty. 1985. Genetic divergence and biology of adaptation in Cicer arietiman. Thero. Appl. Genet. 69: 383-392.

Sachan, K. S. and J. R. Sharma. 1971. Multivariate analysis of genetic divergence in tomato. Indian J. Genet. 31: 86-93.

Saxena, V. K, N. S. Mathi, N. N. Singh and S. K. Vasal. 1998. Heterosis in maize; Grouping and patterns. In: Vasal, S.K., P.C. Gonzales and P. Xingming(cd.) Pro. $7^{\text {th }}$ Asian Reg. Maize workshop los Banos, Philippins, February 23 -27, pp. 124-133.

Smith, M. F. 1990. A multivariate approach to specific problem of grouping maize cultivars. South African J. Plant and Soil 7(3): 167-171.

Thiagarjan, K. R., Rathinaswamy and S. Rajasekaran. 1988. Genetic divergence in cowpea. Madras Agric. J. 75 (3-4): 125-128.

Tomooka, N. 1991. Genetic diversity and landrace differentiation of mungbean (Vigna radiata $\mathrm{L}$.) and evaluation of its wild relatives as breeding materials. Tech. Bull. Crop Res. Center, Japan. No. 28, Ministry of Agr., forestry and Fisheries of Japan. P. 1.

Vasal, S. K.1998. Hybrid maize technology: Challenges and expanding possibilities for research in the next country. In: Vasal, S. K, P. C. Gonzales and P. Xingming (cd. Pro. $7^{\text {th }}$ Asian Reg. Maize workshop los Banos, Philippins, February 23 -27, pp. 58-62. 